\title{
Analysis of 'native' cerebrospinal fluid by the polyacrylamide disc electrophoresis technique
}

\author{
V. R. CUNNINGHAM \\ From the Medical Research Council Research Group on Demyelinating Diseases \\ in the Department of Medicine, Royal Victoria Infirmary and University \\ of Newcastle upon Tyne
}

SYNOPSIS The polyacrylamide disc electrophoresis technique has been applied to the fractionation of 'native' cerebrospinal fluid. Evidence is presented to show that there is an alteration in the protein profile if the fluid is subjected to a concentration stage. A minimum of 22 distinct protein zones have been detected in fluids from patients without structural changes in the nervous system. The method has also been applied to pathological fluids and the differences are discussed.

Fractionation of cerebrospinal fluid by electrophoresis on paper, cellulose acetate, starch, and agar necessitates preliminary concentration of the fluid in order to visualize the separated components by staining. Concentration, whether by pressure dialysis, ultra-filtration or lyophilization, is a tedious process which may, moreover, introduce errors due to possible denaturation of proteins, or loss of components either by adsorption on the membrane or migration through the pores. The present method obviates the need for preliminary concentration.

\section{METHOD}

The method used is based on the polyacrylamide disc electrophoresis technique of Ornstein and Davis (1962) with the 'sample gel' stage omitted. Instead, the anode reservoir was filled with tris buffer, $p \mathrm{H} 8 \cdot 5$, and the sample of cerebrospinal fluid accurately layered over the 'spacer gel' by means of an Agla micrometer syringe according to the method of Fox, Thurman, and Boulter (1963). The sample had been prepared by the addition of sucrose to the fluid to give a final concentration of $25 \%$ sucrose. The optimum range of protein was found to be 250 to $300 \mu \mathrm{g}$., i.e., up to $0.8 \mathrm{ml}$. of spinal fluid was used depending on the protein concentration. Experience showed $11 \mathrm{~cm}$. tubes filled to a height of $6 \mathrm{~cm}$. with 'small pore gel' to be satisfactory. Electrophoresis was carried out at $2 \mathrm{~m}$. amps per specimen for about two hours, by which time the free dye (bromophenol blue) had migrated to the cathode end of the gel. Gels were then stained with $1 \%$ amidoschwartz (naphthalene black 10B, G. Gurr, London) in $7 \%$ acetic acid and destained electrophoretically. The specimens were then evaluated by a Chromoscan densitometer (Ilford 25 filter, orifice $0.4 \mathrm{~cm}$. $\times 0.003 \mathrm{~cm}$., cam B. Joyce Instruments, Newcastle upon Tyne) and also by a

Received for publication 9 September 1963. microdensitometer (Joyce) employing white light; lever ratio 5:1, optical magnification $\times 5$, slit $0.002 \mathrm{~cm}$. $\times$ $0.2 \mathrm{~cm}$., wedge range $0-0.79 \mathrm{D}$.

\section{RESULTS}

Figure 1a shows a typical fractionation of neat cerebrospinal fluid (ref. S). Figure 2 shows a fractionation of the same fluid (after concentration) by the cellulose acetate method of Kohn using 0.05M barbiturate- $\mathrm{HCl}$ buffer $p \mathrm{H} \mathrm{8.2}$. When a specimen of 'normal cerebrospinal fluid', i.e., derived from a patient without structural changes in the nervous system, was fractionated, about 21 protein zones were visualized by the amido-schwartz stain, including two well resolved pre-albumin bands (zones 1 and 2). Some of the zones, e.g., 9, 15, 17, 18, 19, 20, and 22 , were at the limit of visibility and their presence or absence could conceivably be masked by small changes in mobility of larger adjacent zones. Figure $1 \mathrm{~b}$ is the same specimen of cerebrospinal fluid concentrated 10 times by pressure dialysis at $0^{\circ} \mathrm{C}$. overnight in tris-glycine buffer $p \mathrm{H} 8.5$ and fractionated simultaneously with the neat fluid.

Other 'normal' spinal fluids were fractionated and the results are shown in Figures 3 and 4. By measuring the relative mobilities of the different fractions of individual cerebrospinal fluids it is possible to relate one specimen of fluid to another, thereby showing any variation. The present investigation has been carried out using electrophoresis apparatus which can fractionate 12 specimens simultaneously and identical results have been obtained with the same specimen. 

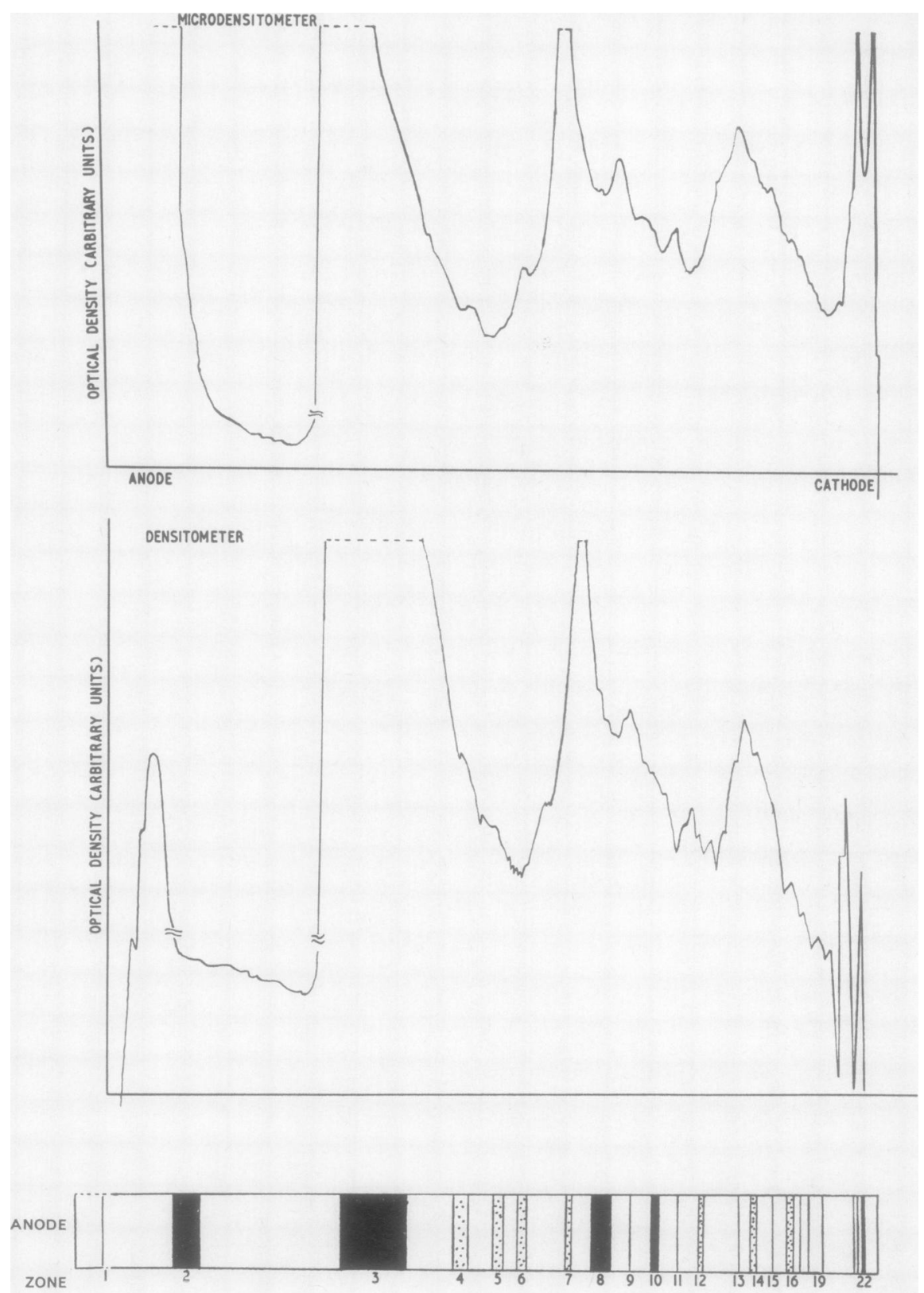

FIG. 1a. Disc electrophoresis of normal cerebrospinal fluid ref. LS; $48 \mathrm{mg}$. protein per $100 \mathrm{ml}$.; $0.7 \mathrm{ml}$. fluid. 

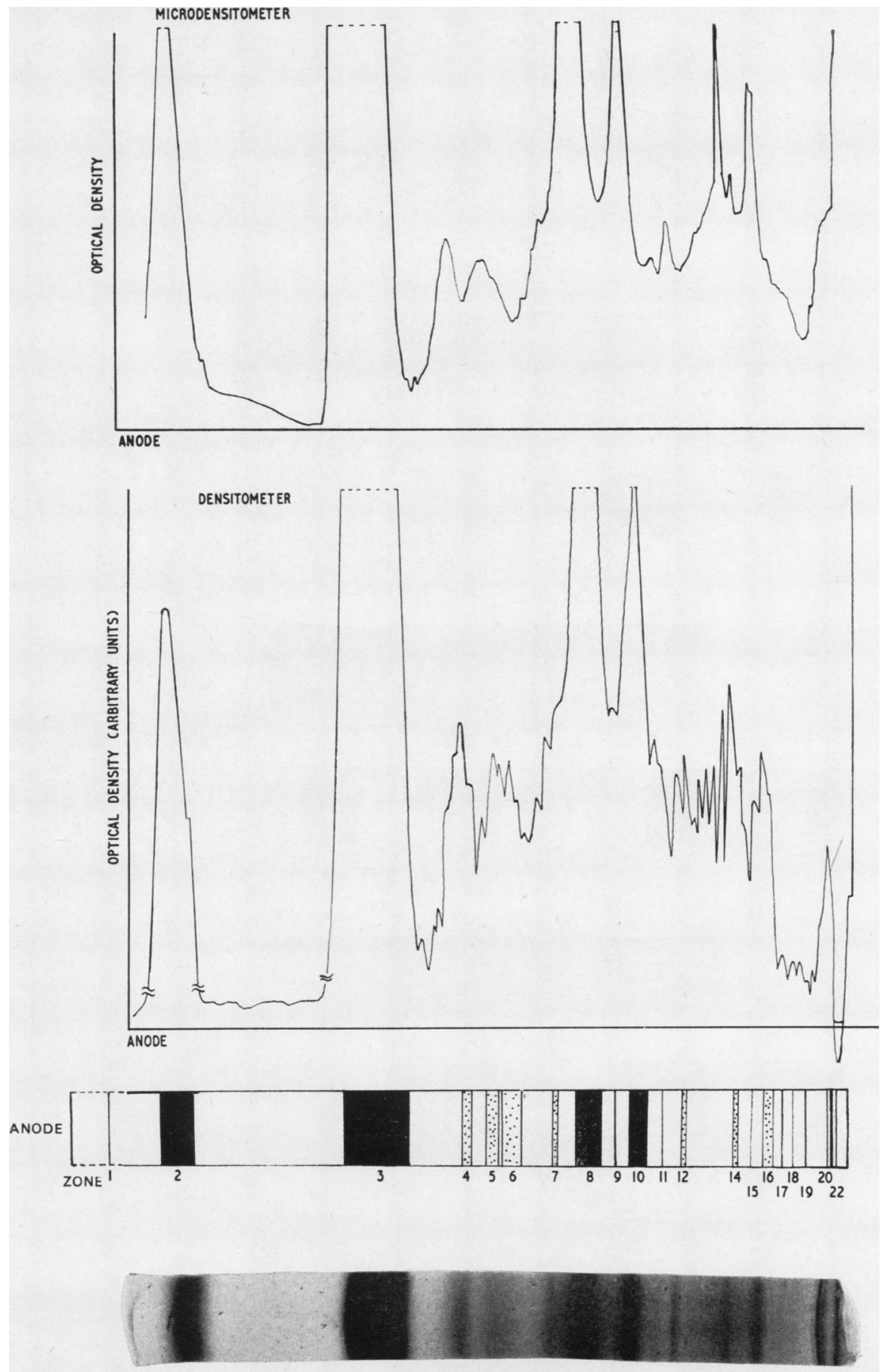

FIG. 1b. Normal cerebrospinal fluid ref. LS. Pressure dialysed $\times 10 ; 0.08 \mathrm{ml}$. concentrated fluid. 


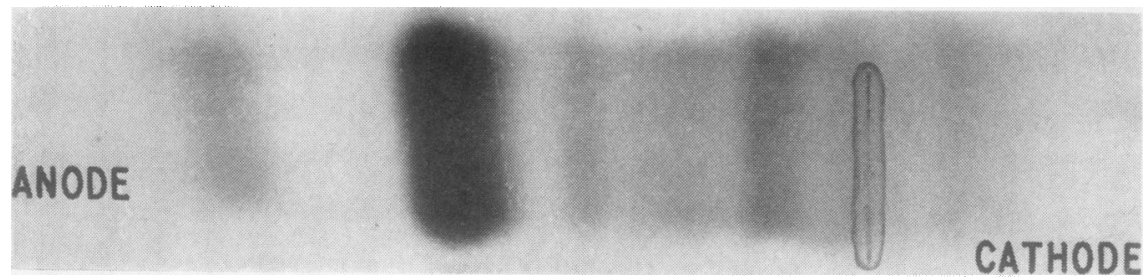

FIG. 2. Cellulose acetate electrophores by the method of Kohn (1957) of cerebrospinal fluid ref. LS concentrated $\times 100$ by pressure FIG. 2 dialysis.

FIG. 3a. Normal cerebrospinal fluid ref. ES; $28 \mathrm{mg}$. protein per $100 \mathrm{ml}$,; $0.8 \mathrm{ml}$.

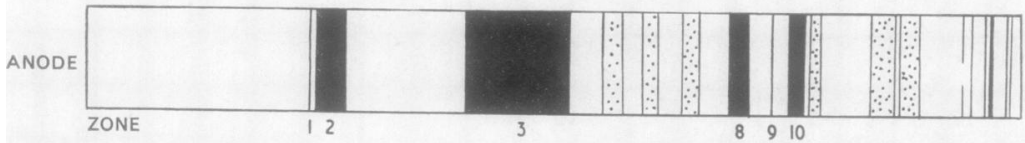
fluid.

FIG. 3a
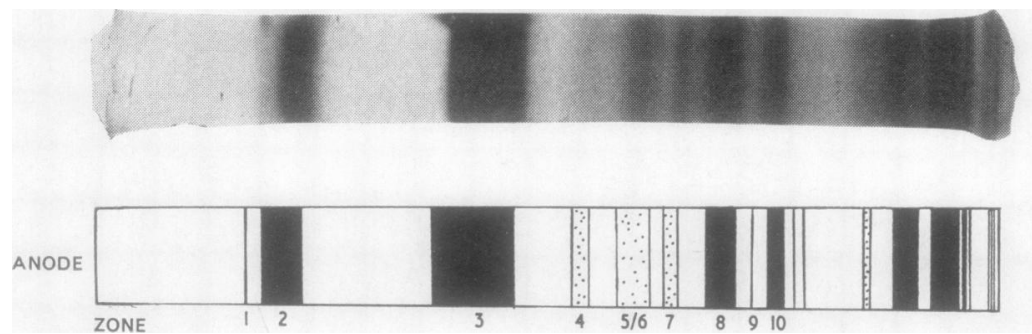

FIG. 3b. Cerebrospinal fluid ref. ES; fluid pressure dialysed $\times 5 ; 0.15 \mathrm{ml}$.

FIG. $3 b$
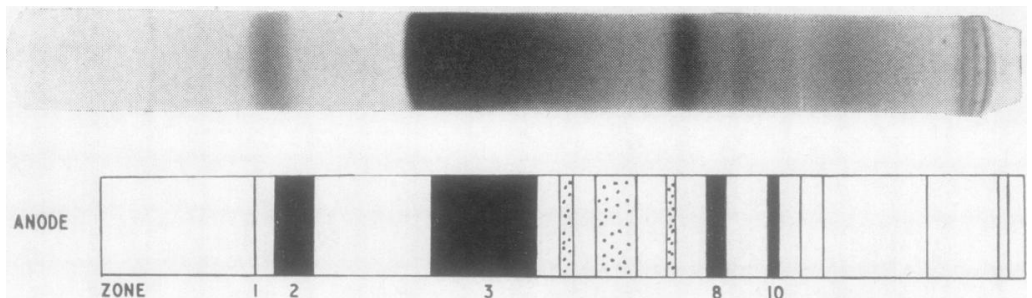
spinal fluid ref. SD; $44 \mathrm{mg}$. protein per $100 \mathrm{ml}$,; $0.7 \mathrm{ml}$. fluid.

FIG. $4 \mathrm{a}$
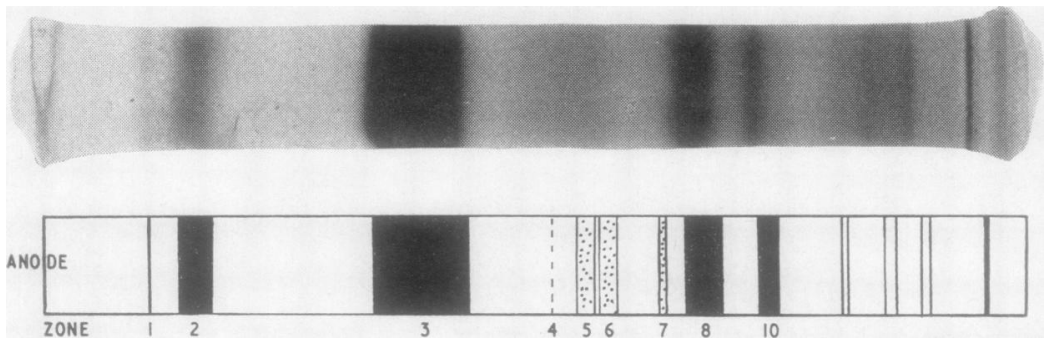

\section{ref. $S D$; fluid pressure} dialysed $\times 5 ; 0.15 \mathrm{ml}$.

FIG. $4 \mathrm{~b}$ 


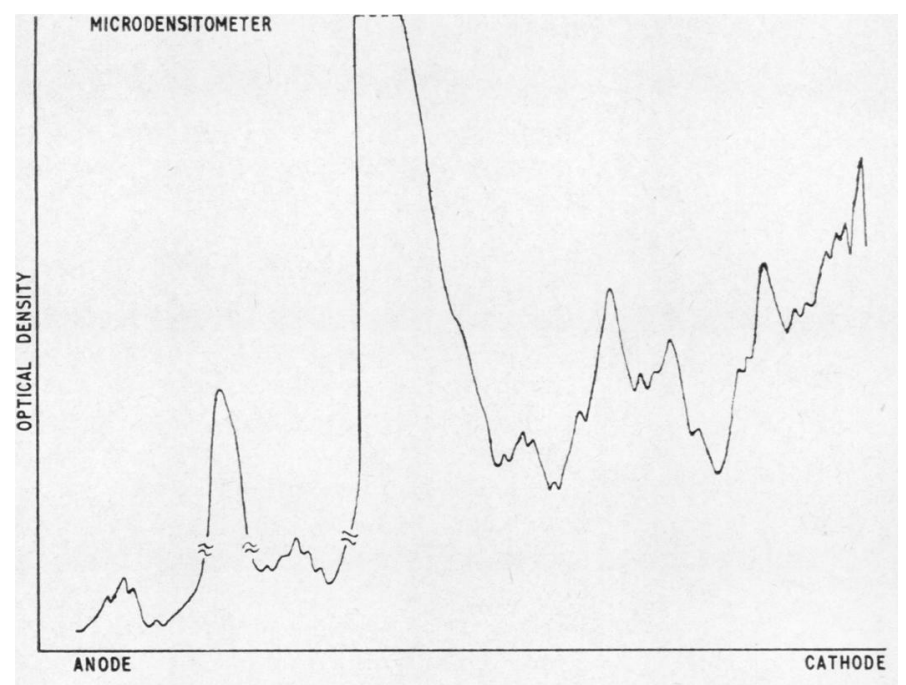

FIG. 5a. Pathological cerebrospinal fluid ref. $A V$ (multiple sclerosis, postmortem specimen); $82 \mathrm{mg}$. protein per $100 \mathrm{ml}$.; $0.3 \mathrm{ml}$. fluid. Note presence of band $2 a$.
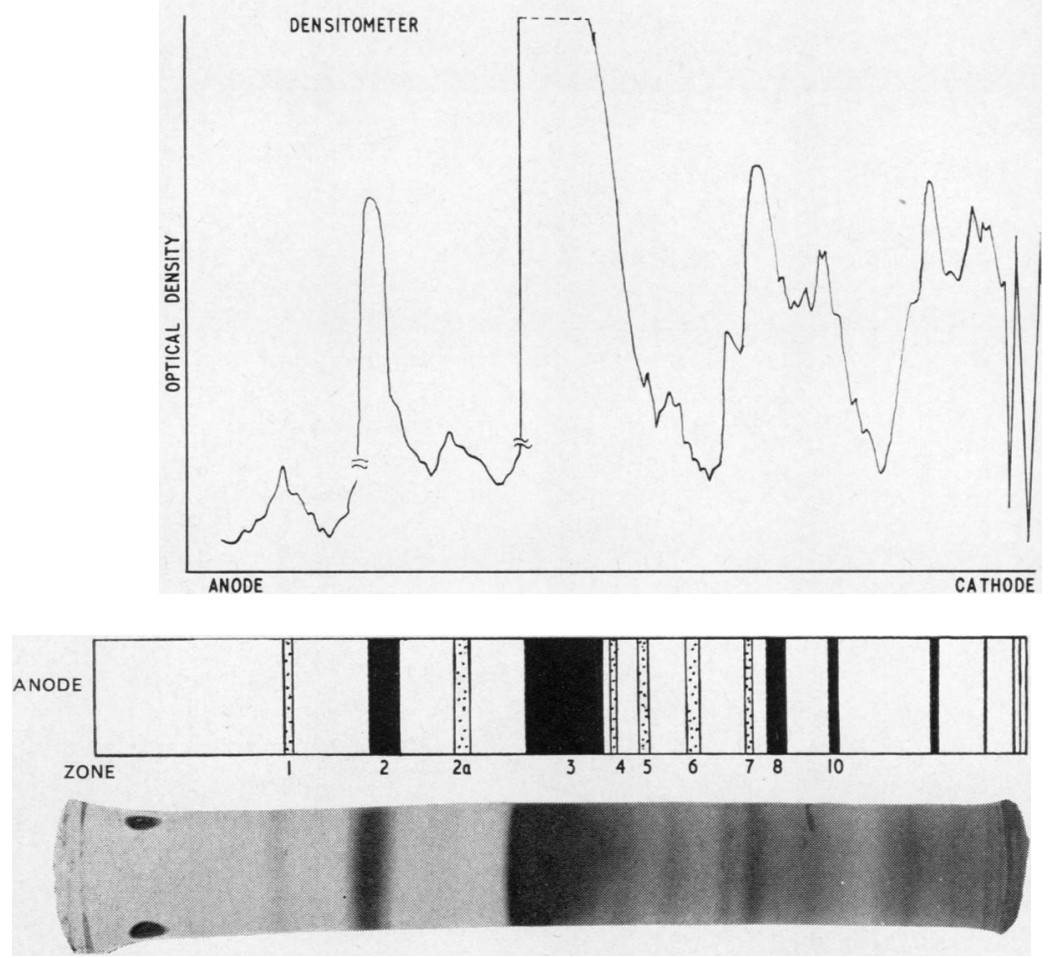

FIG. 5a

FIG. 5b. Cerebrospinal fluid ref. AV; electrophoresis continued until the albumin (zone no. 3) migrated to the end of the gel.

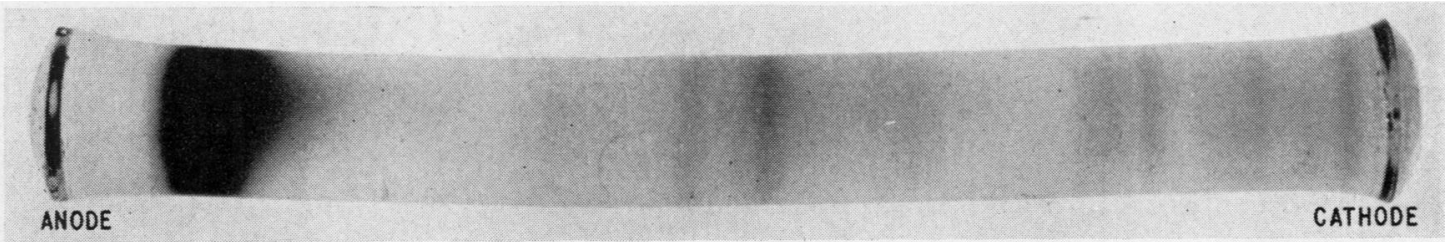

FIG. $5 b$ 

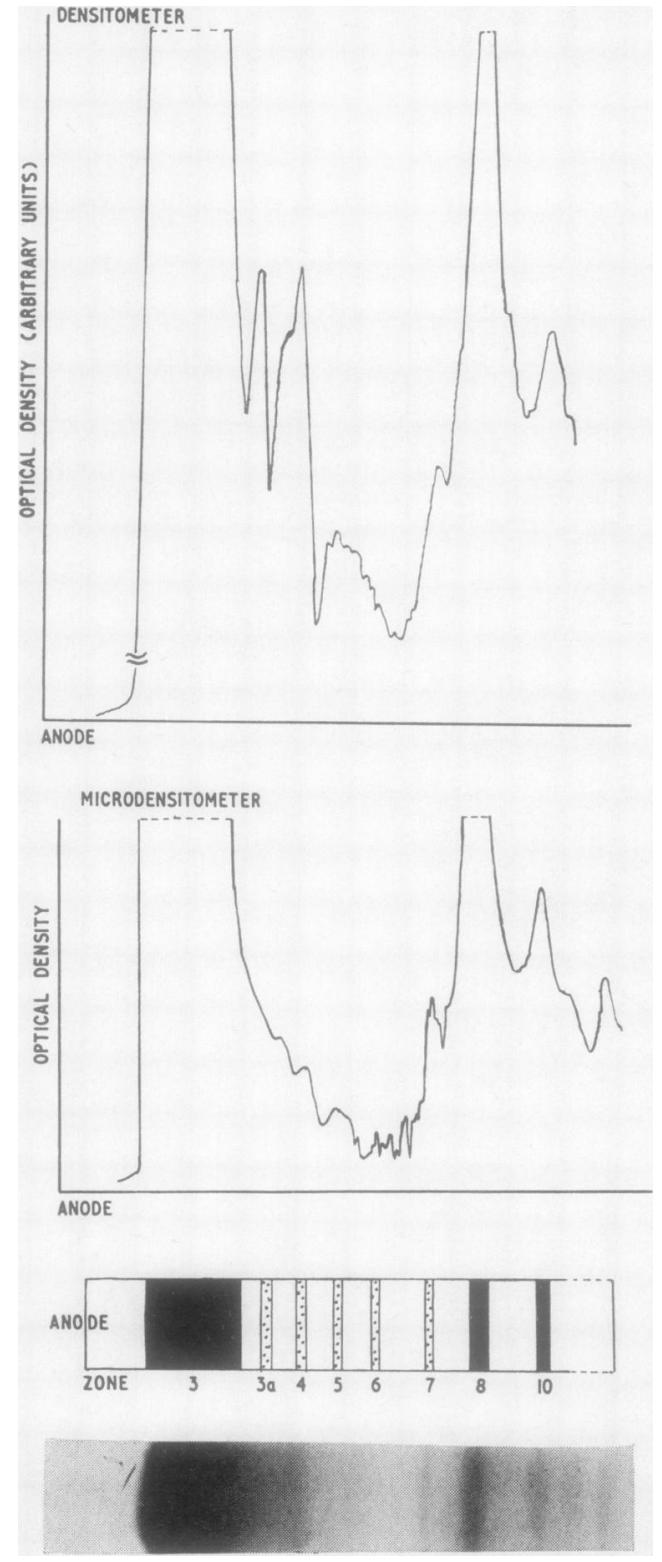

FIG. 6. Pathological cerebrospinal fluid ref. EL (presenile dementia, normal A.E.G.); $52 \mathrm{mg}$. protein per $100 \mathrm{ml}$.; $0.6 \mathrm{ml}$. Note presence of band $3 a$.

As illustrative of the discriminatory capacity of the method, spinal fluid obtained after death from a case of multiple sclerosis was analysed. Figures $5 \mathrm{a}$ and $5 b$ show marked deviations from normal $\stackrel{\stackrel{0}{5}}{\frac{0}{-}}$ similarly, Fig. 6 shows an extra zone in the im $\Rightarrow$ mediate post-albumin region in the spinal fluid of $\frac{a}{2}$ case of presenile dementia.

\section{DISCUSSION}

Consideration of Figs. 1a and $1 \mathrm{~b}$ suggests that con centration of spinal fluid alters its protein pattern in that there is $(a)$ good resolution of zones 3 (albumin) $P$ and 4 in the concentrated fluid whilst the neat fluid shows significant trailing of the albumin band; $(b)$ 出 some alteration in the minor bands near the cathoden (cf. zones 19, 20, and 21 of each gel). In addition, the presence of zone 12 in the concentrated fluid has now definitely been established due to lack of resolution in this area. When neat fluid is examined, however $\vec{\omega}$ zone 12 has always been resolved. With the polyo acrylamide method, genetically-determined protein fractions, such as the haptoglobins, will be visualizedz and some variation in the protein pattern of the smaller components is to be expected. Control experi $\stackrel{\circ}{-}$ ments using human serum were carried out with ande without sucrose in the sample and there appeared top be no obvious differences between the resultanto protein patterns. It was hoped that evaluation of the protein fractions by the two physical methods described might serve for comparison of fluids. Un -0 fortunately, the smaller fractions were not detectedo by either technique and final evaluation of any sample appears, with present methods, to depende on both visual observation and microdensitometry No attempt has been made to evaluate the minot differences in 'scan' given by the two densitometers employed.

The polyacrylamide technique described here is currently being applied to the examination of patho 3 . logical spinal fluids, especially from cases of de-o myelinating disease, in the hope that some specific change(s) may be detected. Meanwhile, the methodo is presented as a rapid, simple, and labour-saving technique.

I would like to thank Dr. C. Simpson of the Royafr Victoria Infirmary, Newcastle upon Tyne, and Dr. G. LN Gryspeerdt of Newcastle Gerieral Hospital for specimens of cerebrospinal fluid, and Messrs. Joyce Loebl (Newcastle upon Tyne) for the use of their chromoscan and microdensitometer.

\section{REFERENCES}

Fox, D. J., Thurman, D. A., and Boulter, D. (1963). Biochem. J., $87 \frac{\mathrm{T}}{0}$ 29P.

Kohn, J. (1957). Clin. chim. Acta, 2, 297. Ornstein, L., and Davis, B. J. (1962). Disc Electrophoresis. New York. $\frac{\stackrel{\rho}{\mathrm{Q}}}{\mathrm{Q}}$ 